\title{
Solid Pseudopapillary Neoplasm of Pancreas, Presentation and Management of a Rare Case
}

\author{
Sana Nasim, Noman Shahzad*, Akbar Mistry, Qurratulain Chundriger and Khwaja Muhammad Inam Pal
}

Aga Khan University Hospital, Karachi, Pakistan

*Corresponding author: Noman Shahzad, General Surgery Office, Link Building, Aga Khan Hospital, Stadium Road Karachi, Pakistan, E-mail: drns01@ @otmail.com

\begin{abstract}
Solid Pseudopapillary Neoplasm (SPN) of the pancreas is a rare neoplasm that typically affects young females. It is a low-grade malignant tumor which is quite commonly misdiagnosed as pancreatic pseudo-cyst. We report a case of SPN in a young female who presented with epigastric pain. Computerized Tomographic (CT) scan of pancreas revealed well demarcated lesion in the head of pancreas. She underwent Whipple procedure. Histopathology confirmed the diagnosis. She did not need any further treatment.
\end{abstract}

Keywords: Epigastric pain; Pancreas; Solid pseudopapillary neoplasm

Received Date: April 24, 2018; Accepted Date: May 05, 2018; Published Date: May 12, 2018

\section{Introduction}

Solid Pseudopapillary Neoplasm (SPN) of the pancreas was first described by Frantz [1]. It has been categorized under an uncommon pathologic entity with low malignant potential [2] which mainly affects young women [3,4]. According to Martin et al. [5], there has been a rise in the diagnosis of SPNs over time but still it is a rare neoplasm accounting for $0.2 \%-2.7 \%$ of the primary pancreatic tumors. Theses neoplasms grow slowly and have excellent prognosis [6]. SPNs is also known as papillary epithelial neoplasm, solid and cystic acinar cell tumor, papillary cystic neoplasm, papillary cystic carcinoma, solid and cystic tumor, low-grade papillary tumor, and Frantz's tumor [5]. In 1996 this tumor was termed as Solid Pseudopapillary Tumor (SPPT) by the World Health Organization (WHO) for the international histological categorization of tumors of the exocrine pancreas [7]. Proper and accurate diagnosis of SPPT requires complete awareness of clinical, microscopic and macroscopic features besides adequate sampling of tumor [8].

\section{Case Report}

We report a case of a 27 year old female who presented in the general surgery clinic with complains of progressively worsening epigastric pain, inability to tolerate solid diet and early satiety for 3 months. Physical examination was unremarkable except decreased muscle mass. Computerized Tomographic (CT) scan of Chest and Abdomen showed a welldefined, lobulated soft tissue mass $(4.6 \mathrm{~cm} \times 3.1 \mathrm{~cm} \times 5.7 \mathrm{~cm})$ involving the head and neck of the pancreas (Figure 1 and

Citation: Noman Shahzad, Solid Pseudopapillary Neoplasm of Pancreas, Presentation and Management of a Rare Case. J Clin Cases Rep 2018: 1(2): 58-62. DOI: https://doi.org/10.46619/joccr.2018.1-1013 
Figure 2). No evidence of metastasis was found on CT scan. To characterize it further fine needle aspiration cytology (FNAC) was done under endoscopic ultrasound guidance which suggested a papillary neoplasm.

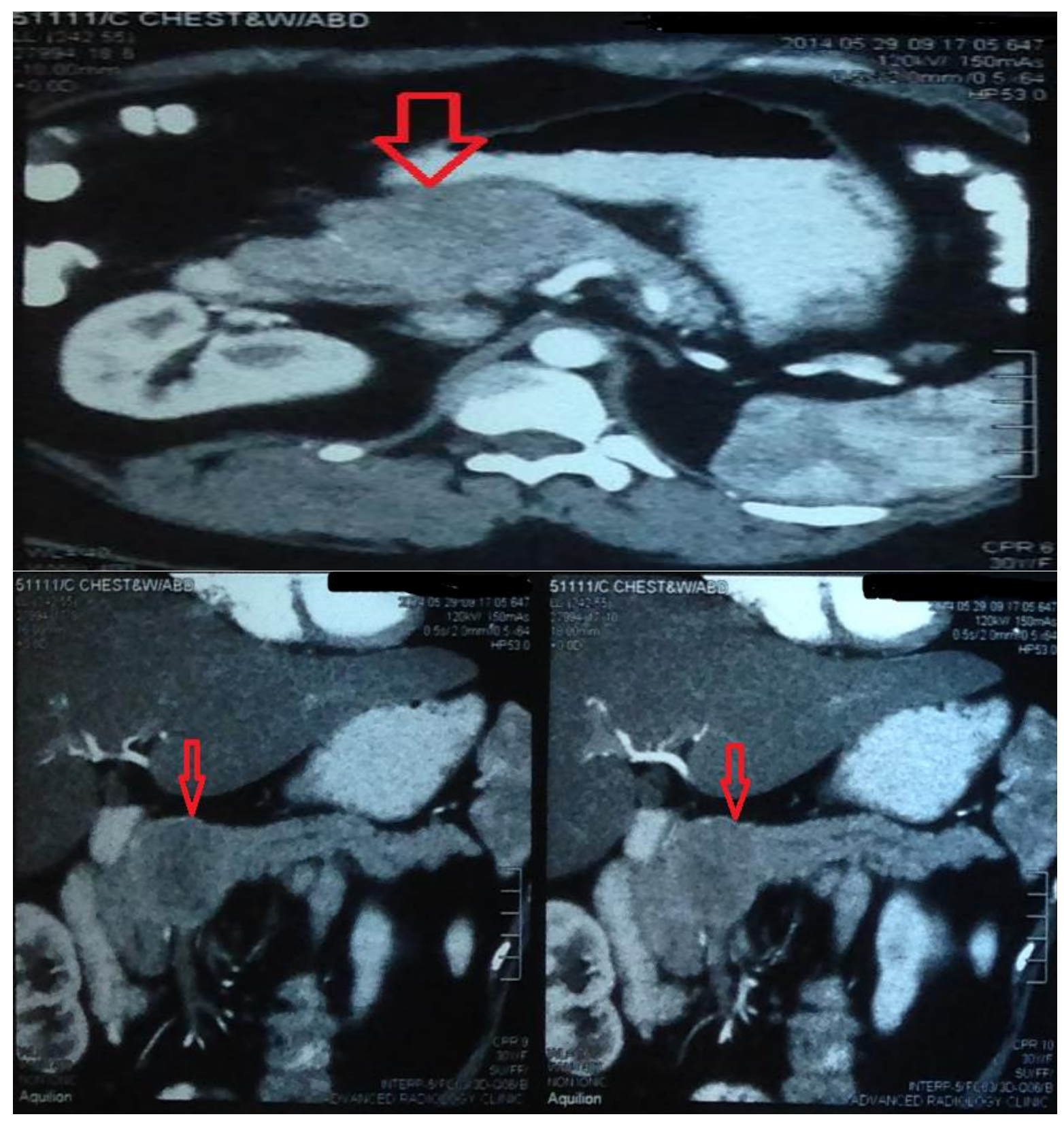

Figure 1: CT-Scan images showing a well-defined, lobulated soft tissue mass involving region of the head and neck of the pancreas. Heterogeneous appearance of the lesion is due to central necrosis.

The patient underwent Classic Pancreaticoduodenectomy (Whipple's procedure) through a Cheveron incision. She recovered well post-operatively. She was kept on enteral diet through feeding jejunostomy, while her oral diet was progressed gradually. She developed wound infection which was managed conservatively and was discharged on antibiotics and daily dressings. Two months post-surgery, she is doing well. The histopathology report confirmed the diagnosis of SPN. Grossly the tumor was well circumscribed, with a yellow brown appearance and firm consistency. On microscopy, the tumor was composed of solid nests of cells with numerous small blood vessels. Pseudopapillary architecture with hyalinized fibrovascular cores lined by several layers of epithelial cells was seen owing to discohesiveness of cells away from the blood 
vessels. Cells with round and oval nuclei, finely stippled chromatin, indistinct nucleoli and few mitoses were also seen (Figure 3).

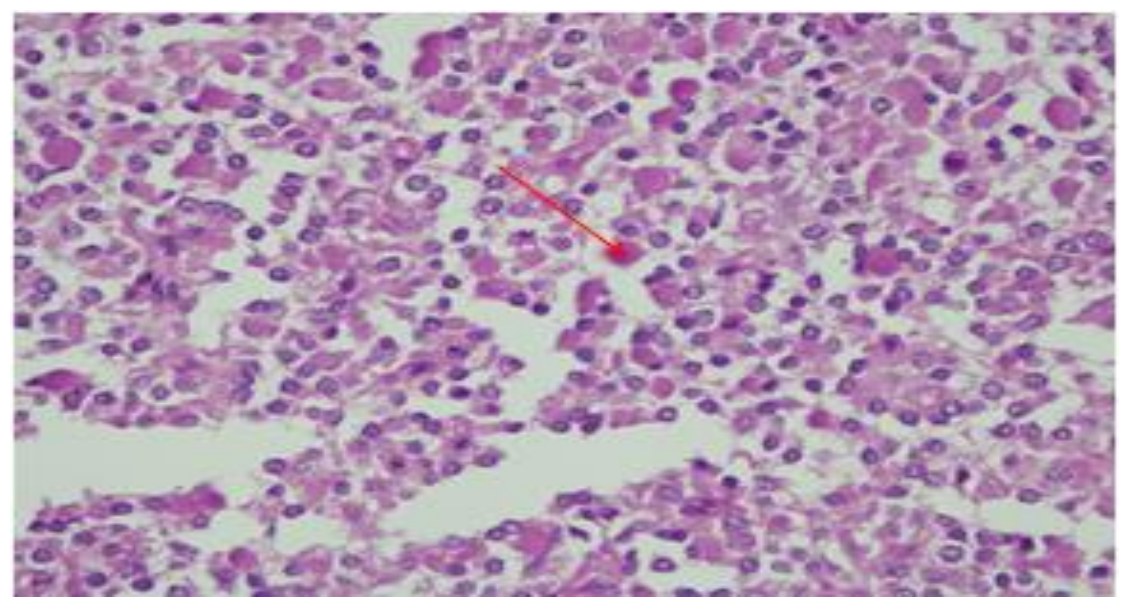

Figure 2: (H\&E 40x) The tumor cells have moderate amount of foamy to eosinophilic cytoplasm, with bland, round to oval nuclei and longitudinal grooves. Numerous large hyaline globules are seen in the cytoplasm of tumor cells (Arrow).

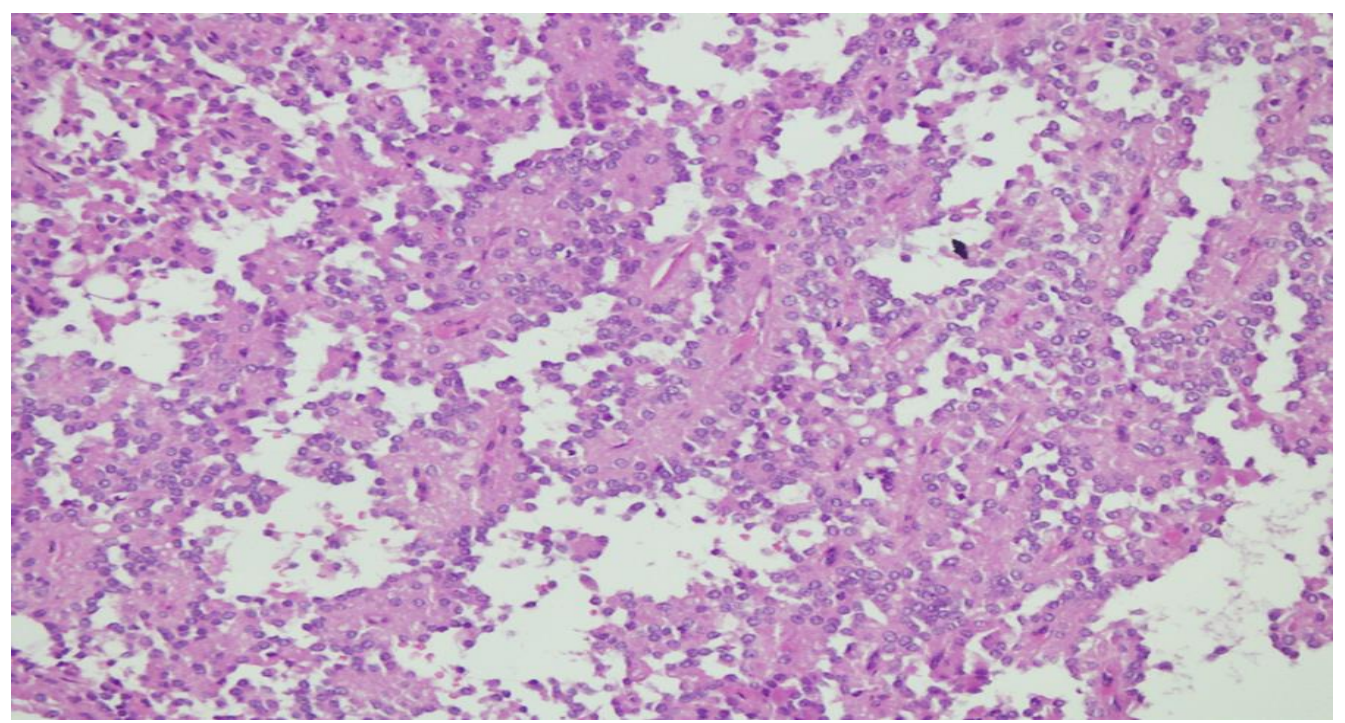

Figure 3: At higher magnification, the central vessel is easily seen by a rim of eosinophilic cytoplasm which separates it from the tumor cells. (H\&E 10x).

This case was discussed in our Multi-Disciplinary Tumor (MDT) Board meeting. No further adjunctive treatment was planned.

\section{Discussion}

Solid Pseudopapillary Neoplasm (SPN) is encountered in young women between 20 and 30 years of age [9], and is most commonly reported in those of Asian origin. In a report around 20\% of the reported SPN cases were in children [10]. Though pancreaticobiliary tumors in children are known to be aggressive, management is decided considering individual situations [11]. Although rare, SPN is not totally absent among men [12]. Because the tumor is most commonly found in females, and progesterone receptors are present in these cases, it has been suggested that SPN is a hormone dependent tumor [13]. 
www.tridhascholars.org | July-2018

The cell of origin of SPN is unknown [14]. According to some authors SPN is the neoplasm of uncommitted cells and most the cells have some similarity with intercalated duct cells or centoacinar cells [15].

Upper abdominal pain is among the very common symptoms of SPN, almost half the patients complain of this symptom. Although SPN can be present anywhere in the pancreas, its most common site is the head or tail [16].

The typical CT scan features of SPN include a big well encapsulated mass having solid and cystic components due to hemorrhagic degeneration [15]. Calcifications and enhancing solid areas may be found at periphery of mass. Uncommon appearances include: metastasis to liver, ductal obstruction, extracapsular invasion, dense calcification and male patients. Solid pseudopapillary neoplasms show positive nuclear staining for beta catenin, as well as positive immunostaining for CD10, CD56, vimentin, alpha 1-antitrypsin, and neuron specific enolase; they are negative for chromogranin and pancreatic enzymes [17].

According to a report venous invasion, diffuse growth pattern, extensive tumor necrosis, significant nuclear atypia and high mitotic rate come under the indicators of malignant potential of SPN [18]. WHO classification categorizes malignant SPNs as solid-pseudopapillary carcinomas [15].

The differential diagnosis of SPN consists of pseudocyst of pancreas, neuroendocrine tumor and ductal adenocarcinoma of pancreas. Normally it is only after operative biopsy has been done that a diagnosis of SPN is confirmed. In contrast to ductal adenocarcinoma of pancreas, SPN has very good prognosis. It is possible for the benign SPN to turn malignant, but surgical excision is curative [19]. Overall five year survival of the patients has been reported to be as high as $97 \%$ in patients who undergo resection [20].

\section{Conclusion}

Encapsulated lesion in pancreas discovered on contrast enhanced CT scan of abdomen whose features are not typical of adenocarcinoma warrant microscopic evaluation which can be done through fine needle aspiration cy tology.

\section{References}

1. Frantz V (1959) Tumors of the pancreas, Atlas of Tumor Pathology. Washington DC: Armed forces Institute of Pathology 32-33.

2. Compagno J, Oertel J, Kemzar M (1979) Solid and papillary epithelial neoplasm of the pancreas, probably of smallduct origin: a clinico-pathological study of 52 cases. Lab Invest 40: 248-249.

3. Oertel J, Mendelsohn G, Compagno J (1982) Solid and papillary epithelial neoplasms of the pancreas. Pancreatic Tumors in Children 167-171.

4. Vassos N, Agaimy A, Klein P, et al. (2013) Solid-pseudopapillary neoplasm (SPN) of the pancreas: case series and literature review on an enigmatic entity. International Journal of Clinical and Experimental Pathology 6(6): 1051.

5. Martin RC, Klimstra DS, Brennan MF et al. (2001) Solid-Pseudopapillary Tumor of the Pancreas: A Surgical Enigma? Annals of Surgical Oncology 9(1): 35-40.

6. Chen X, Zhou G, Zhou H, et al. (2005) Diagnosis and treatment of solid-pseudopapillary tumors of the pancreas. International Journal of Hepatobiliary and Pancreatic Diseases 4: 456-459. 
7. Kloppel G, Solcia E, Longneckar D, et al. (1996) World Health Organization :Institutional histological classification of tumors - histological typing of tumors of the exocrine pancreas (2nd ed.). Berlin, Germany: Springer-Verlag.

8. Sharma P, Lal H (2011) Pseudopapillary Tumor of Pancreas. Journal of Medical Education \& Research 199-201.

9. Kaufman S, Reddick R, Steigel M (1986) Papillary cystic neoplasms of the pancreas: a curable pancreatic tumor. World Journal of Surgery 10(5): 851-856.

10. Kaste S (2008) The Pancreas. Caffey's Pediatric Diagnostic Imaging. Mosby: Elsevier.

11. Parveen A, Shahzad N, Khan S, et al. (2018) Aggressive Gallbladder Cancer in A Young Child Presenting as Acute Pancreatitis. Case Reports and Literature Review 2(1): 100005.

12. Lam KY, Lo CY, Fan ST (1999) Pancreatic solid-cystic papillary tumor: Clinicopathologic features in eight patients from Hong Kong and review of the literature. World Journal of Surgery 23(10): 1045-1050.

13. Jung SE, Kim DY, Park KW, et al. (1999) Solid and papillary epithelial neoplasm of the pancreas in children. World Journal of Surgery 23(3): 233-236.

14. Oerte J, Oertel Y, Heffes C (1999) Pancreas, Diagnostic surgical pathology 3rd edn. Philadelphia: Lippincott, Williams and Wilkins.

15. Pettinato G, Manivel J, Ravetto C (1992) Papillary cystic tumor of the pancreas: a clinicopathological study of 20 cases with cytologic, immunohistochemical, ultrastructural and flow cytometric observations and a review of the literature. American Journal of Clinical Pathology 98: 478-488.

16. Coleman K, Doherty M, Bigler S (2003) Solidpseudopapillary tumors of the pancreas. Radiographics 1644-1648.

17. Lubezky N, Papoulas M, Lessing Y, et al. (2017) Solid pseudopapillary neoplasm of the pancreas: Management and long-term outcome. European Journal of Surgical Oncology (EJSO) 43(6): 1056-1060.

18. Nishihara K, Nagoshi M, Tsuneyoshi M (1993) Papillary cystic tumor of pancreas: assessment of their malignant potential. Cancer 71: 82-92.

19. Reddy S, Cameron JL, Scudiere J, et al. (2009) Surgical management of solid-pseudopapillary neoplasms of the pancreas (Franz or Hamoudi tumors): a large single-institutional series. Journal of the American College of Surgeons 208(5): 950-957.

20. Eder F, Schulz HU, Rocken C, et al. (2005) Solid-pseudopapillary tumor of the pancreatic tail. World Journal of Gastroenterology 11: 4117-4119. 